\title{
Synthesis and Characterization of Nickel and Zinc Sulfide Ethylenediamine Complexes
}

\author{
S. Abd El Mongy", R. Seoudi ${ }^{2}$ and A. A. Shabaka \\ 1) Physics Department, Faculty of Girls of Science and Arts, Ain Shams \\ University, Cairo, Egypt. \\ 2) Spectroscopy Department, Physics Division, National Research \\ Center, Dokki, Cairo , Egypt.
}

\begin{abstract}
In the present work, nickel and zinc sulfides ethylendiamine $\left(\mathrm{N}_{2} \mathrm{H}_{4} \mathrm{C}_{2} \mathrm{H}_{4}\right)$ complexes were prepared in an autoclave at $180{ }^{\circ} \mathrm{C}$ for $12 \mathrm{~h}$. Transmission electron microscope (TEM) and X-ray powder diffraction were used to study the morphology of the two samples. The infrared absorption spectra were obtained and discussed in the range (200-4000 $\left.\mathrm{cm}^{-1}\right)$. New bands appeared at about 238,240 and $297 \mathrm{~cm}^{-1}$ assigned to Ni-S and Zn-S vibration coupled with metal nitrogen vibration. The data indicate that, the nickel and zinc sulfide were synthesized as complexes with ethylenediamine. Thermogravimetric analysis (TGA) shows three main regions. The first region is attributed to dehydration, the second is due to degradation and the third is due to carbonization. The electrical properties were measured in the temperature range (300-400 K), the activation energy was calculated and discussed.
\end{abstract}

\section{Introduction:}

Transition metal catalysts have received special attention and in particular, some metal oxides, such as $\mathrm{TiO}_{2}$ and $\mathrm{ZnO}$ have been extensively studied and used as materials for environmental protection [1,2]. Transition metal sulfide, such as CdS and ZnS, well know catalytic semiconductor. Metal complexes are known to have good catalytic properties in organic synthesis, and some systems have been used as sensitizer for photolysis of water [3, 4], but there are few examples that were used for wastewater treatment. Nickel sulfides have important applications in hydrogenation catalysis, especially in the organic synthesis procedures [5], among which $\alpha-\mathrm{NiS}$ and $\mathrm{Ni}_{3} \mathrm{~S}_{2}$ have been reported as important of catalytic compounds [6, 7]. Moreover, NiS possesses interesting electronic properties due to its metal-insulator, paramagnetic-antiferromagnetic phase change [8-10]. 
The present study is devoted to the preparation of $\mathrm{ZnS}$ and $\mathrm{NiS}$ ethylenediamine complexs. The obtained complexes were characterized by transmission electron microscopic, x-ray diffraction, and infrared spectroscopy. The thermal and electrical properties were measured.

\section{Experimental}

The solvothermal elemental reaction was used for the preparation of $\mathrm{ZnS}$ and $\mathrm{NiS}$ ethylenediamine complexes. An appropriate amount of $\mathrm{ZnCl}_{2}$, $\mathrm{NiCl}_{2}$ and sulfur powder $(99.95 \%)$ was added to $80 \mathrm{ml}$ of ethylenediamine in a Teflon-lined autoclave of $100 \mathrm{ml}$ capacity. Then the autoclave was sealed and maintained at $180^{\circ} \mathrm{C}$ for $12 \mathrm{~h}$ without shaking. The precipitate was filtered off, washed with distilled water and absolute ethanol, respectively, and then dried in a vacuum at $80^{\circ} \mathrm{C}$ for $4 \mathrm{~h}$.

The microstructures and the particle distribution were investigated by Transmission electron microscope (Zeiss EM 10) operating at $100 \mathrm{kV}$. The complexes powder was prepared by making a suspension from the powder in distilled water. The suspension was sinterfuge to collimate the large size particles. Then a drop of the suspension was put into the carbon grid and left to dry at $100^{\circ} \mathrm{C}$.

X-ray diffraction pattern was measured using (A Philips PW 1370) $\mathrm{X}$-ray diffractometer operating at $35 \mathrm{kV}$ and $15 \mathrm{~mA}$, using a monochromated Ni-filter, CuKa radiation $(\lambda=1.54 \mathrm{~nm})$, a scanning rate of $2 \theta / \mathrm{min}$, and a range of $4 \leq 2 \theta \leq 80$. A Jasco Model 300E Fourier Transform Infrared Spectrometer was used to measure the vibrational spectra of the investigated samples. Thermogravimetric analysis was carried out in nitrogen atmosphere, at a heating rate of $10{ }^{\circ} \mathrm{C} \quad \mathrm{min}^{-1}$ using the computerized Perkin Elemer (U. S., Norwalk, C. T) TGA7-Unix system series.

The DC electrical conductivity of the samples was obtained out on samples in the form of disc of about $0.85 \mathrm{~cm}$ diameter and $0.16 \mathrm{~cm}$ thick. The two surfaces of each sample were coated with silver paint (BDH) and checked for good contact. The DC-conductivity was carried out from room temperature up to $400 \mathrm{~K}$ and measured using Keithly electrometer type $6517 \mathrm{~A}$. The temperatures were measured by K-type thermocouple connected to Digi-Sense thermometer. The junction of thermocouple was in contact with the sample. The accuracy of measuring temperature was better than $\pm 1^{\circ} \mathrm{C}$. 


\section{Results and Discussion:}

Figure $(1 \mathrm{a}, \mathrm{b})$ shows the images of transmission electron microscopy (TEM) of NiS and $\mathrm{ZnS}$ ethylenediamine complexes. From this figure, it is noticed that, the morphology is different for the two samples and this is due to the different formed aggregation of $\mathrm{NiS}$ and $\mathrm{ZnS}$ in the ethylenediamine. The physical and chemical properties of the two metals play an important role of this aggregation.

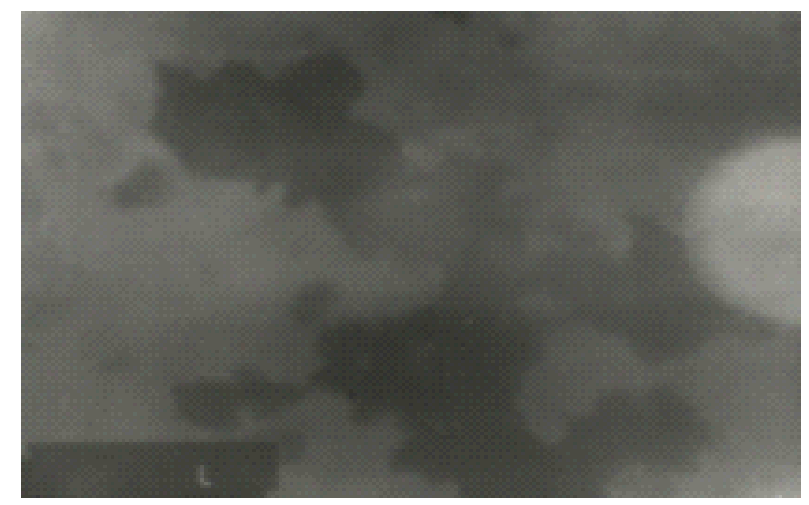

(a)

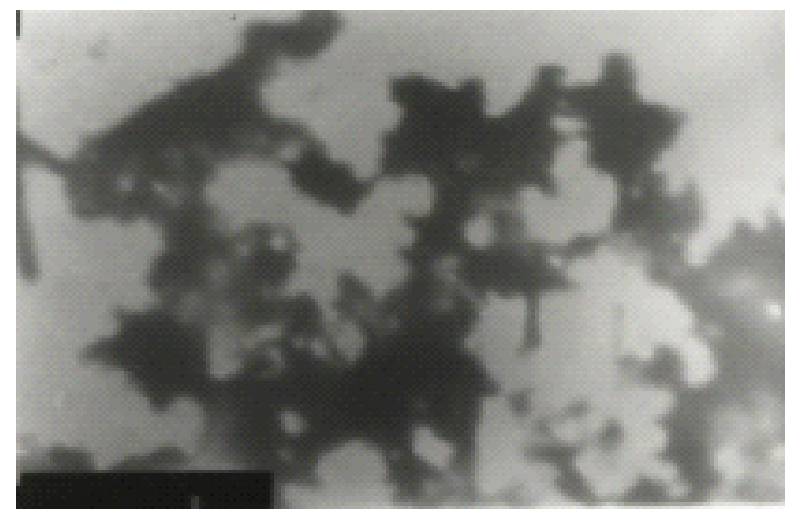

(b)

Fig. (1: a, b): Transmission electron microscope (TEM) of

(a) NiS ethylenediamine complex. (b) ZnS ethylenediamine complex.

Figure $(2 \mathrm{a}, \mathrm{b})$ represent the X-ray diffraction patterns of the two samples under investigation. By comparing the d values of NiS form [JCPDS, card No., 83-0575] with the d values of NiS formed it was found that, the two values are different. Also, the d values of $\mathrm{ZnS}$ form [JCPDS, card No. 36-1450] disappeared in the $\mathrm{ZnS}$ formed. These indicate that, the two new compounds are not $\mathrm{NiS}$ and $\mathrm{ZnS}$ but it is a complexes with ethylenediamine and can be written in the form [NiS(en) and $\mathrm{ZnS}(\mathrm{en})]$. 


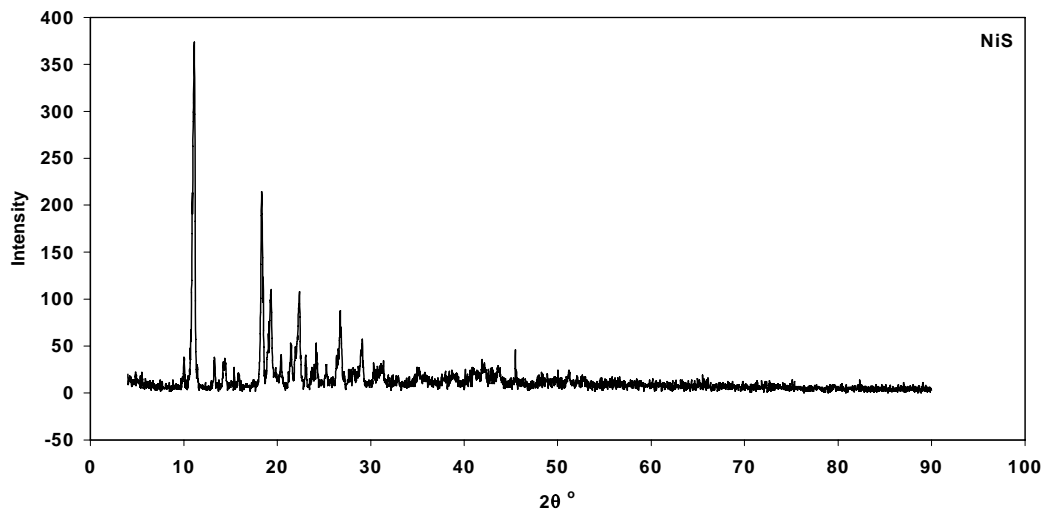

(a)

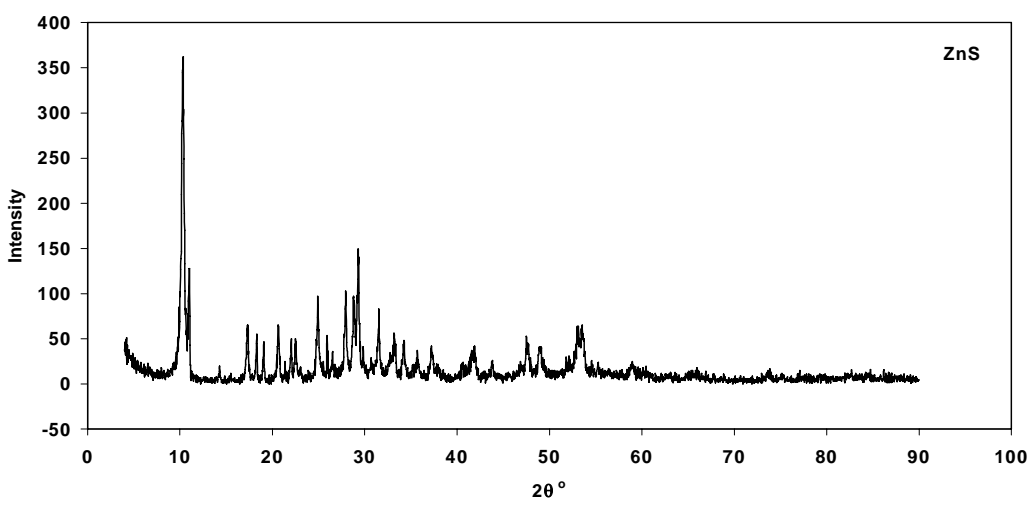

(b)

Fig. (2): XRD pattern of (a) NiS ethylenediamine complex and (b) $\mathrm{ZnS}$ ethylenediamine complex.

The infrared absorption spectrum in the wavenumber range (4000-400 $\mathrm{cm}^{-1}$ ) of ethylenediamine (en) is shown in Fig. (3a). From this figure it was shown that, the NH stretching vibration was appeared at 3357 and $3281 \mathrm{~cm}^{-1}$. The $\mathrm{CH}$ symmetric and asymmetric stretching vibrations of $\mathrm{CH}_{2}$ groups were observed at 2927 and $2855 \mathrm{~cm}^{-1}$ respectively. The absorption band appeared at $1598 \mathrm{~cm}^{-1}$ is most likely due to $\mathrm{NH}$ deformation vibration. To give clear information about the molecular structure changes the infrared spectrum of $\mathrm{NiS}(\mathrm{en})$ and $\mathrm{ZnS}$ (en) of (en) was compared with that of en It can be noticed that, the spectra of NiS(en) and $\mathrm{ZnS}(\mathrm{en})$ are quite different than the spectrum of (en). IR absorption spectra of the prepared samples are shown in Fig. (3b, c). The NH vibration at 3357 and $3281 \mathrm{~cm}^{-1}$ for the (en) shifted to lower wavenumber at $\left(3295\right.$ and $\left.3169 \mathrm{~cm}^{-1}\right)$ in the spectrum of NiS(en) and at (3239 and $3115 \mathrm{~cm}^{-1}$ ) in the spectrum of $\mathrm{ZnS}(\mathrm{en})$. This shift is du to the coordination 
of the metal with ethylendiamine through the lone pare of electrons on the nitrogen atom. The bands appeared at $238 \mathrm{~cm}^{-1}$ in the spectrum of NiS Fig. (4a) due to the Ni with coordinated with the nitrogen atom. The two bands appeared at about $240 \mathrm{~cm}^{-1}$ and $297 \mathrm{~cm}^{-1}$ for ZnS Fig. (4b) may be due to coordinated $\mathrm{Zn}$ with nitrogen and sulfur atom.

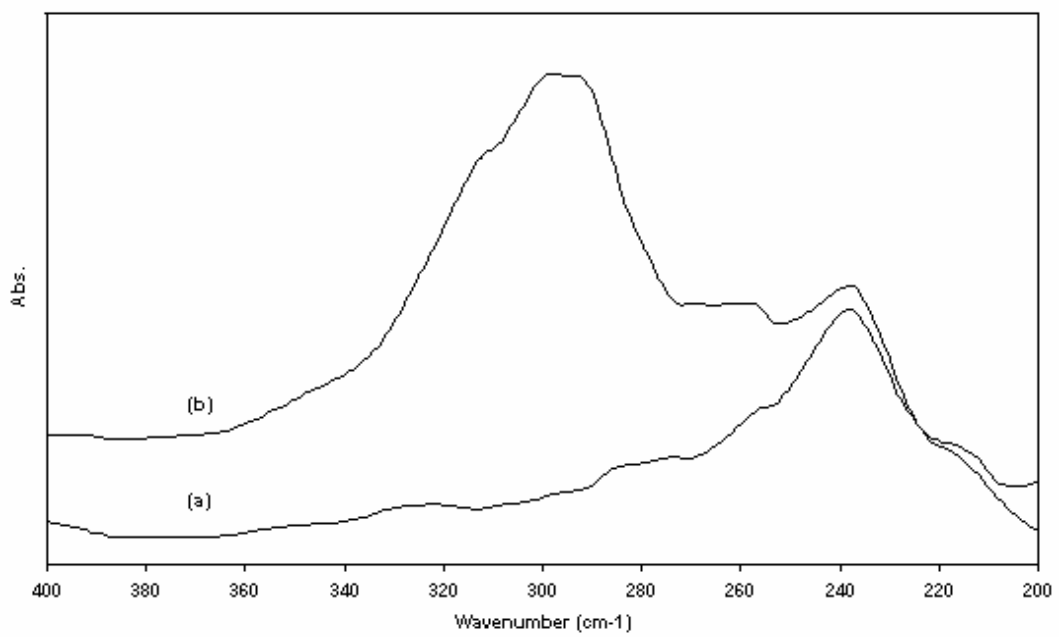

Fig.(3): Infrared absorption spectra of (a) NiS ethylenediamine complex and

(b) $\mathrm{ZnS}$ ethylenediamine complex in the range $\left(400-200 \mathrm{~cm}^{-1}\right)$

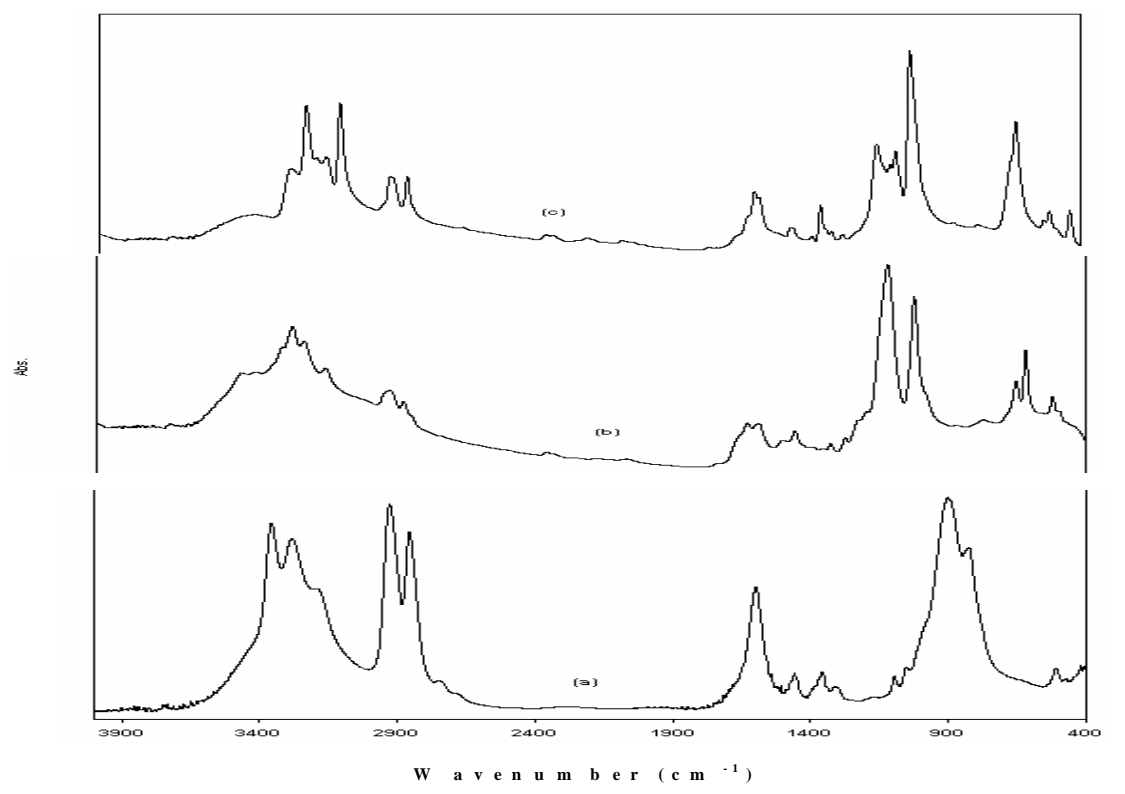

Fig.(4): Infrared absorption spectra of (a) ethylenediamine, (b) NiS ethylenediamine complex and (c) $\mathrm{ZnS}$ ethylenediamine complex in the range $\left(4000-400 \mathrm{~cm}^{-1}\right)$ 
Thermogravimetric analysis (TGA) was used to study thermal stability in the temperature range from $30{ }^{\circ} \mathrm{C}$ to $800{ }^{\circ} \mathrm{C}$ for the samples under investigation (Fig. 5). Figure $(5, \mathrm{~b})$ shows that more than one region for each sample are observed. The loss of weight nearly constant with temperature in the first region started from $30{ }^{\circ} \mathrm{C}$ for two samples and ended at about $100{ }^{\circ} \mathrm{C}$ for NiS(en) and $\mathrm{ZnS}$ (en) complexes. The second region ended at 250 and $340{ }^{\circ} \mathrm{C}$ with loss of weight 10 and $14 \%$ for the two samples respectively. This is due to the moisture evaporation and generation of noncombustible gases such as $\mathrm{CO}, \mathrm{CO}_{2}$. The main decomposition region ended at about $540{ }^{\circ} \mathrm{C}$ with loss of weight 50 and $70 \%$ for the two samples respectively. This is most probably due to generation of combustible gases [11]. The last decomposition region represents the thermal degradation of the anhydride. The thermal activation energy was calculated by analyzing TGA data by differential method [12]. Plotting $\log \left[\left(\mathrm{w}_{\mathrm{o}}-\mathrm{W}_{\infty}\right) /\left(\mathrm{w}_{\mathrm{t}^{-}}-\mathrm{w}_{\infty}\right)\right]$ against time $(\mathrm{t})$, where $\mathrm{w}_{\mathrm{o}}$ is the initial weight, $\mathrm{w}_{t}$ is the weight at time $t$ and $\mathrm{w}_{\infty}$ is the weight of the ash remaining after the final heating. As shown from Fig. (6a, b), a two linear part are noticed, the first part occurred due to the water evaporation and the second line is due to thermal decomposition. The activation energy of the main decomposition temperature is calculated using Arhenius plot for the first order reaction [13-15]. The values of the activation energy of NiS(en) and $\mathrm{ZnS}(\mathrm{en})$ complexes were 146.6 and $225.2 \mathrm{KJmole}^{-1}$. From these two values, it is seen that the activation energy of $\mathrm{ZnS}(\mathrm{en})$ is higher than that of NiS(en). This is due to the occupied of $3 \mathrm{~d}$ orbital of $\mathrm{Zn}$ metal.

The dependence of DC electrical conductivity on the reciprocal absolute temperature $(1 / \mathrm{T})$ may be defined using the relation $\sigma=\sigma_{0} \exp ^{-\Delta \mathrm{E} / \mathrm{kT}}$ [16], where, $\sigma$ is the conductivity, $\sigma_{0}$ represents the value of $\sigma$ at $(1 / \mathrm{T})=0$, T is the absolute temperature and $\mathrm{k}$ Boltzman's constant and $\Delta \mathrm{E}$ is the electrical activation energy. Two regions are observed for nickel and zinc sulfide complexes. In the first region from room temperature up to $370 \mathrm{k}$, all impurity atoms are ionized and the extrinsic carriers are not yet excited to a marked degree. This is because the density of carriers remains approximately constant and equal to the impurity concentration. Therefore, the temperature dependence on the conductivity is decided by carrier mobility. The conductivity increases with increasing temperature in the second region which started form $370 \mathrm{k}$ and ended at $400 \mathrm{k}$. In this region the activation energy $(0.95 \mathrm{eV})$ is associated with a short-lived charge transfer between impurity and the complex. This region corresponds to an intrinsic region [11]. For zinc sulfide the conductivity nearly decrease with increasing temperature in the region $(300-380 \mathrm{k})$. In this region the main scattering mechanism was scattered by thermal vibrations and the mobility decreases with rising temperature so the conductivity will decreases within this region. In the second region (380-400) the conductivity was increased with increasing temperature with activation energy $(2.65 \mathrm{eV})$ and it is the same behavior of nickel sulfide. 

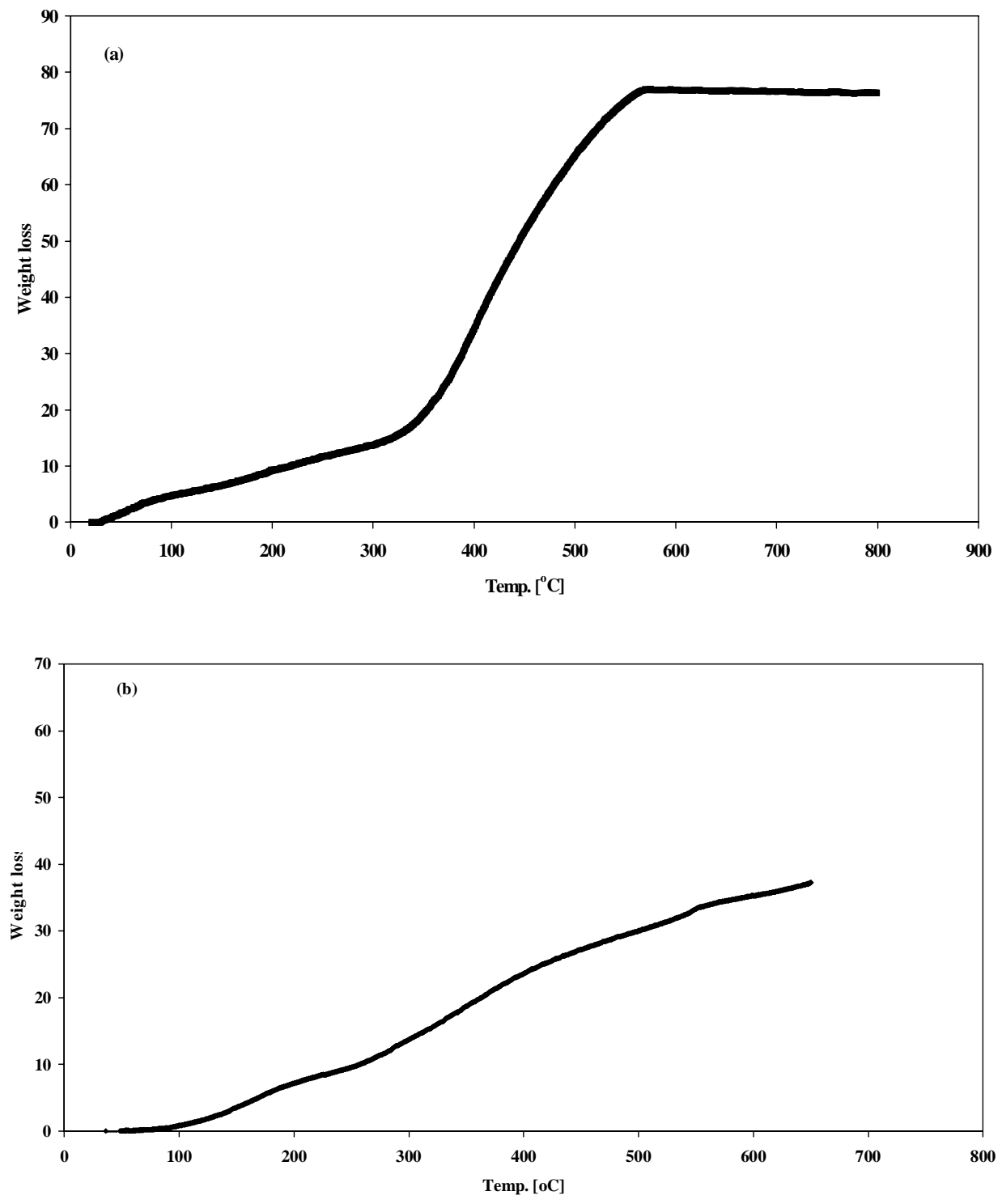

Fig.(5): Thermal gravimetric analysis of (a) NiS ethylenediamine Complex and (b) $\mathrm{ZnS}$ ethylenediamine complex 

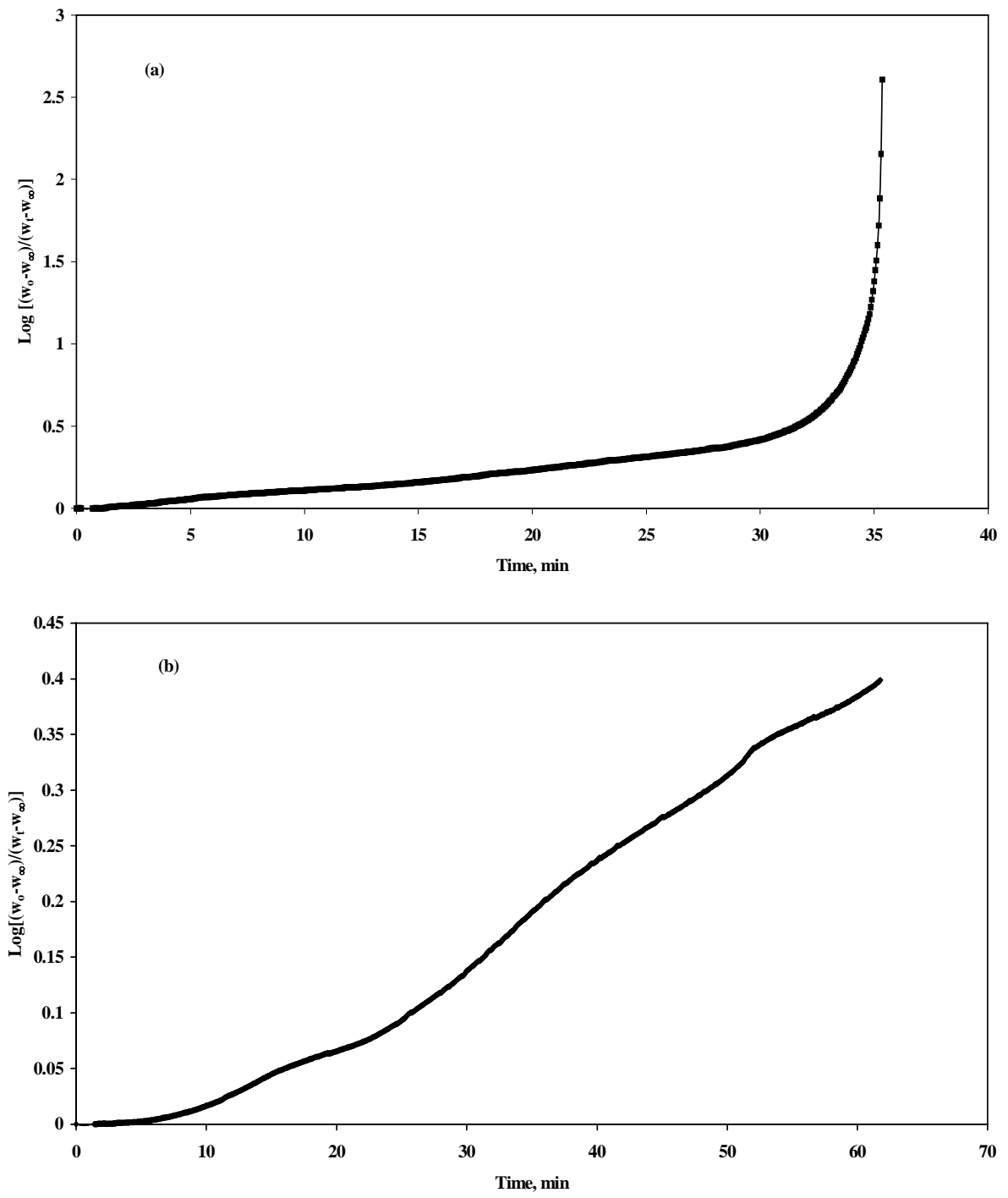

Fig. (6): Relation of $\log \left[\left(\mathrm{W}_{\mathrm{o}}-\mathrm{W}_{\infty}\right) /\left(\mathrm{W}_{\mathrm{t}}-\mathrm{W}_{\infty}\right)\right]$ versus time for (a) NiS ethylenediamine complex and (b) $\mathrm{ZnS}$ ethylenediamine complex. 

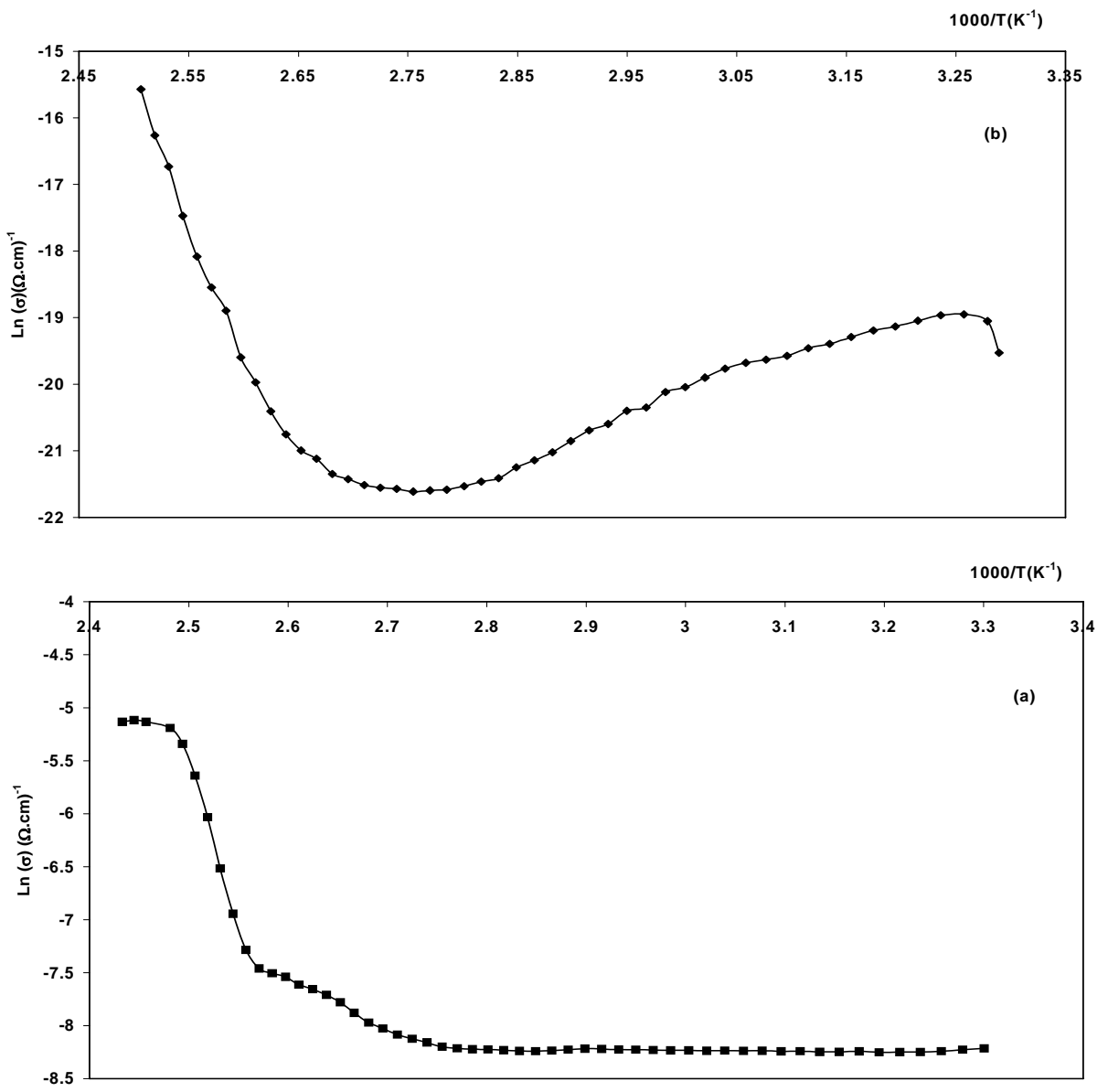

Fig. (7): Variation of DC electrical conductivity $(\sigma)$ with reciprocal of absolute $1000 / \mathrm{T}(\mathrm{K})$ for (a) NiS ethylenediamine complex and

(b) $\mathrm{ZnS}$ ethylenediamine complex

\section{Conclusion:}

The phase and size of the nickel and zinc sulfide were studied from $\mathrm{X}$-ray powder diffraction and transmission electron microscope. The results indicated that the two new compound ( $\mathrm{NiS}$ and $\mathrm{ZnS}$ ) complexes with ethylenediamine[NiS(en) and $\mathrm{ZnS}(\mathrm{en})]$ were formed. The complexes were confirmed by appeared of new band at about $300 \mathrm{~cm}^{-1}$ which assigned to Ni-S and $\mathrm{Zn}-\mathrm{S}$ vibration coupled with metal nitrogen vibration. The thermal properties indicated that, the decomposition region depend on the physical properties of both $\mathrm{Ni}$ and $\mathrm{Zn}$ metal. The semiconducting behaviors were observed for two samples from DC measurements. The electrical activation energy was estimated. 


\section{References:}

1. D. F. Ollis, in: H. Al-Ekabi (Ed.), "Photocatalytic Purification and Treatment of Water and Air", Elsevier, Amsterdam, (1993).

2. M. R. Hoffmann, S.T. Martin, W. Choi, D. W. Bahnemann, Chem. Rev. 95, 69 (1995).

3. A. J. Bard, M. A. Fox, Acc. Chem. Res. 28, 141 (1995).

4. M. Hara, C.C. Waraksa, J. T. Lean, B. A. Lewis, T. E. Mallouk, J. Phy. Chem. A 104, 5275 (2000).

5. O. Weisser, S. Landa, "Sulfide Catalysts, Their Properties and Applications", Pergamon, Oxford, New York, 167 (1973).

6. Y. Yermakov, A. N. Startsev, V. A. Burmistrov, Appl. Catal. 11, 1 (1984).

7. K. I. Tanaka, T. Okuhara, Catal. Rev. -Sci. Eng. 15, 249 (1977).

8. J. T. Sparks, T. Komoto, Phys. Lett. 25A, 398 (1967).

9. J. Trahan, R. G. Goodrich, S. F. Watkins, Phys. Rev. B2, 2859 (1970).

10. D. B. Mcwhan, M. Marezio, J.P. Remeika, P. D. Darnier, Phys. Rev. B 5, 2552 (1972).

11. S. Ambily, C.S. Menon, Thin Solid Films 347, 284 (1999).

12. S. Glsastone, "Textbook of Physical Chemistry", London, Macmilan (1962).

13. M. El-Sakhawy, J. Therm. Anal. Cal., 63, 549 (2001).

14. A. M. Kaloustain and J. Pastor, J. Therm. Anal. Cal., 63 (1), 7 (2001).

15. Arthur Von Hippel, "Dielectric Materials and Applications", Artech House, Boston, London (1995).

16. S. I. Shihub, R. D. Gould, Thin Solid Films, 254, 187 (1995). 